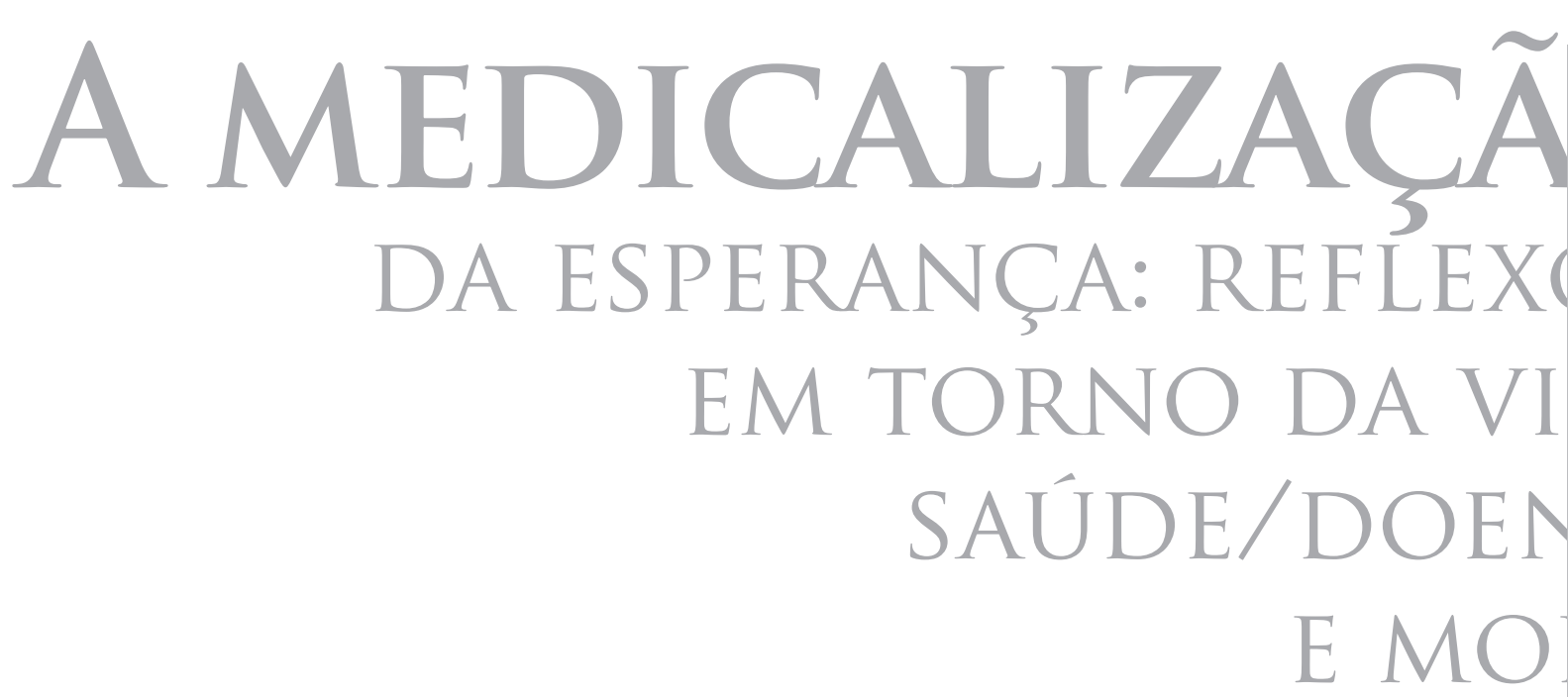




\section{A MEDICALIZAÇÃO DA ESPERANÇA: REFLEXÕES EM TORNO DA VIDA, SAÚDE/DOENÇA E MORTE}

\section{RACHEL A I N S E G A R T M E N E Z E S}

UNIVERSIDADE FEDERAL DO RIO DE JANEIRO, BRASIL 


\title{
A MEDICALIZAÇÃO DA ESPERANÇA: REFLEXÕES EM TORNO DE VIDA, SAÚDE/DOENÇA E MORTE
}

\section{Resumo}

Este artigo aborda o processo de transformação dos sentidos da esperança, ocorrido a partir da secularização da sociedade ocidental moderna. Com a perda da transcendência e a ênfase na fisicalidade e no hedonismo, a categoria esperança torna-se objeto de medicalização, adquirindo novos significados. O texto explicita como o aparato biomédico passou a lidar com a produção de esperanças em relação à saúde e a construção de uma "morte com dignidade", após a segunda metade do século XX. A análise é empreendida com base em levantamento bibliográfico sobre a temática. Os debates em torno das esperanças "legítimas" - ou não se centram, sobretudo, no destaque concedido ao direito de autonomia individual, o que denota a preeminência de valores morais vigentes em cada contexto examinado.

Palavras-chave: Vida e morte, esperança, medicalização.

\section{THE MEDICALIZATION OF HOPE: REFLECTIONS ABOUT LIFE, HEALTH/SICKNESS AND DEATH}

\begin{abstract}
This article tackles the process of transformation of the meanings of hope, which has sprung from the secularization of modern Western society. With the loss of transcendence and the emphasis on physicality and hedonism, the hope category became an object of medicalization, acquiring new meanings. The text explains how the biomedical apparatus began to deal with the production of hope in relation to health and the construction of a "death with dignity", after the second half of the 20th century. The analysis is performed based on bibliographical survey of the thematic. The debates around hope that is "legitimate" - or not - mostly center on the emphasis placed upon the right to individual autonomy, which denotes the preeminence of current moral values in each examined context.
\end{abstract}

Keywords: Life and death, hope, medicalization 


\section{LA MEDICALIZACIÓN DE LA ESPERANZA: REFLEXIONES SOBRE VIDA, SALUD/ENFERMEDAD Y MUERTE}

\section{Resumen}

Este artículo discute el proceso de transformación de los sentidos de la esperanza, producido a partir de la secularización de la sociedad occidental moderna. Con la pérdida de la trascendencia y el énfasis en la corporalidad y el hedonismo, la categoría esperanza se convierte en objeto de medicalización, adquiriendo nuevos significados. El texto explicita cómo el aparato biomédico pasó a ocuparse de la producción de esperanzas en relación a la salud y de la construcción de una 'muerte con dignidad', después de la segunda mitad del siglo XX. El análisis se realiza en base a los estudios bibliográficos sobre el tema. Los debates en torno a las esperanzas "legítimas" - o no - se centran, sobre todo, alrededor del destaque concedido al derecho de autonomía individual, lo que denota la preeminencia de los valores morales imperantes en cada contexto examinado.

Palabras-clave: Vida/muerte; esperanza; medicalización.

Endereço da autora para correspondência: Rua Conde de Irajá $\mathrm{n}^{\circ}$ 43, apto 401, Botafogo, Rio de Janeiro RJ, CEP 22271-020. E-mail: raisengartm@terra.com.br 
"Hope has been medicalised, and thus secularised. My image of eclipse is thoroughly appropriate here. It is not that medicine has somehow dynamited eternity out of the universe, simply that the practice of medicine stands between us and eternity and we no longer can see it. [...] Medicine has eclipsed eternity". (Tony Walter, The eclipse of eternity 1996a: 83)

\section{INTRODUÇÃO}

O homem não vive sem esperança. Em face do mal, seja ele de origem climática - como as chuvas (excesso ou falta), geológica - como terremotos e erupções de vulcão -, ou humana - como as guerras ou enfermidades -, são construídas chaves explicativas e propostas de intervenção, dirigidas ao restabelecimento do equilíbrio. Nessas situações ocorre uma produção do sentimento de esperança, capaz de mobilizar crenças e práticas, em grupos e sociedades.

No que concerne aos males que podem atingir a pessoa, destacam-se duas instituições, relativamente à esperança: a religião e a biomedicina. Ambas foram - e se mantêm - responsáveis pela produção de sentidos e de sentimentos em torno do sofrimento. Indo além, a elas foram e seguem sendo - atribuídos os encargos da construção de esperanças.

$\mathrm{Na}$ sociedade ocidental moderna e, sobretudo, na contemporânea, observase um processo de transformação da esperança - ou, segundo Peter Burke (2012: 207), das esperanças. Para este autor, a esperança é uma categoria que varia de acordo com a época, com o lugar e, também, segundo a inserção social. Assim, distintas pessoas têm esperança de diferentes objetos e/ou metas: de vida eterna, felicidade neste mundo, saúde, riqueza material, posição social, segurança, amor, fama, reconhecimento, entre outras possibilidades.

Ainda para Burke (2012: 207), há três tipos de história das esperanças: uma psico-história, nos moldes da história do medo (Delumeau 1989), do amor, da raiva e de outras emoções. $\mathrm{O}$ segundo tipo de história está intrinsecamente associado ao primeiro, pois é, para este autor, uma história social. $\mathrm{Na}$ atualidade, os objetos da esperança e as situações nas quais emergem este sentimento estão associados a determinadas instituições, capazes de promover uma produção de expectativas: "desde a familia até a telenovela” (Burke 2012: 208). A sociologia histórica poderia, ainda, discutir os nexos entre esperanças e eventos econômicos e políticos. A terceira abordagem se centra no estudo das grandes tradições de esperança: a religião e suas instituições. Tal posicionamento converge com o enfoque de Robert Marret (1932: 28), que postula ser a esperança o "sentimentomãe" da religião.

A esperança está implícita em situações de revolta, revolução e de transformações sociais ou pessoais. Para Vincent Crapanzano (2003: 45), é “o campo do desejo na espera”. Portanto, trata-se de uma categoria intimamente vinculada à temporalidade, pois pressupõe a possibilidade de um futuro. Indo além, significa a probabilidade e a expectativa de realização de desejo, em outro momento. 
De acordo com Burke (2012: 208), é possível distinguir dois continentes na cartografia histórica dos sonhos: os grandes e os pequenos. O primeiro concerne a temas e ideias que atingem a humanidade em sentido genérico, como a justiça ou a ética. Já o segundo se refere a questões da vida cotidiana. Este autor aponta, ainda, a existência de "tempos de esperança" (Burke 2012: 212). A Revolução Francesa, o governo Kennedy e o período desenvolvimentista do governo de Juscelino Kubitschek, no caso do Brasil, são exemplos destes tempos. Desse modo, a esperança possui uma história social, cultural, política e econômica. Mas, mais do que a constatação da existência deste sentimento ao longo da história, o que os estudos sobre as expectativas evidenciam é sua recorrência e continuidade, o que indica sua relevância, para a vida em sociedade.

Este artigo é dedicado ao exame do processo de transformação dos sentidos da esperança, a partir da secularização da sociedade ocidental moderna. Em especial, aborda este constructo, no que concerne ao adoecimento e ao processo do morrer, em decorrência de enfermidade crônica degenerativa. Para tanto, são apresentados estudos recentes sobre a temática, tanto no Brasil como em outros contextos.

\section{PROCESSO HISTÓRICO, DOENÇA E ESPERANÇA}

As doenças têm história e cada época possui "suas" enfermidades (Adam \& Herzlich 2001: 15). No passado, as epidemias eram uma constante. Elas variaram: desde a lepra no século VI; a "peste negra" no XIV; da Idade Média até o século XVIII a varíola; no século XV a sífilis; no XVII a tuberculose, o tifo, entre outras doenças, até a AIDS, no final da década de 1980 e início dos anos 1990. Essas epidemias - e outras configuraram uma vivência do adoecimento e do falecimento como fenômenos coletivos. Em pequenas aldeias e cidades, praticamente todas as famílias e grupos eram afetados. As pessoas conheciam o curso da doença e, ao serem infectadas, tinham consciência da proximidade de sua própria morte. Assim, elas tomavam decisões e se preparavam espiritual e materialmente para o término de suas vidas.

Em épocas antigas, nascimento e morte - como outros aspectos animais da vida humana - eram eventos mais públicos e, portanto, mais sociáveis e menos privatizados do que no século XX (Elias 2001: 25). Na sociedade medieval, a vida era mais curta do que na contemporaneidade; os perigos, menos controláveis; o sentido da culpa e o medo da punição após a morte, a doutrina oficial, proveniente da religião. $\mathrm{Na}$ iminência do falecimento, a autoridade máxima era o religioso, capaz de perdoar o moribundo, temente do Juízo Final. A esperança era a salvação da alma.

$\mathrm{Na}$ transformação deste horizonte ocorreram dois importantes processos: o civilizatório (Elias 1994), com duração de cerca de quatro ou cinco séculos; a mudança nos saberes médicos (Foucault 1994), com uma nova configuração do hospital e de seu personagem principal, o médico (Foucault 1979). 
De acordo com Walter (1996b: 193), as formas de enfrentamento da morte se alteraram, com o processo de secularização da sociedade ocidental. $\mathrm{Na}$ sociedade tradicional, os costumes e a religião ditavam o comportamento dos atores sociais e, consequentemente, as esperanças também eram regidas por estas instituições. A dor, o sofrimento físico e moral eram centrais, para a meta da absolvição. O religioso fornecia uma linguagem para o preparo da alma, em sua jornada após a vida. Os rituais da morte produziam nos viventes o terror e a esperança, em relação ao Julgamento Final (Walter 1996b: 195). A entrada no Céu era o sonho de ricos e pobres.

Com o nascimento do hospital como instrumento terapêutico - uma invenção datada do final do século XVIII - este horizonte se transforma significativamente (Foucault 1979: 99). Antes do século XVIII, o hospital era uma instituição de assistência aos pobres. A função do hospital, até esta mudança histórica e epistemológica, era dirigida ao pobre em processo do morrer. $\mathrm{O}$ hospital era um morredouro, e o pessoal que ali trabalhava fazia uma obra de caridade, com a intenção de salvar sua própria alma.

Em uma longa trajetória histórica, o hospital se medicalizou. A reorganização desta instituição consistiu no primeiro passo do amplo processo de medicalização, ocorrido a partir de uma tecnologia política, a disciplina (Foucault 1979: 105).

Assim, "é a introdução dos mecanismos disciplinares no espaço confuso do hospital que vai possibilitar sua medicalização" (Foucault 1979: 107). Vale acrescentar a existência de outro processo, à mesma época: a transformação do saber e da prática médicas. No ajuste desses dois processos - o deslocamento da intervenção médica e a disciplinarização do espaço hospitalar - encontra-se a origem do hospital médico. Neste ambiente nasce e se desenvolve um importante personagem: o médico, detentor de saberes e de poderes sobre a vida e a morte humana. A expertise do cientista e do médico tornam-se relevantes referências na cultura ocidental moderna. O religioso deixa de ser a autoridade máxima, no que concerne ao morrer. Este ator social é substituído paulatinamente em importância pelo médico.

O sofrimento perde sentido e a centralidade do dolorismo cristão (Sahlins 1997; Duarte 2004: 43) se esvai. O hedonismo se torna uma característica primordial da modernidade. Da centralidade da transcendência passa-se à ênfase na fisicalidade.

No Ocidente, um longo processo histórico fez com que a esperança e a confiança não mais fossem depositadas exclusivamente nas mãos de autoridades religiosas, a partir do advento da modernidade. A emergência do indivíduo como valor e o colapso da comunidade acarretaram a diluição da autoridade da tradição (Walter 1996b: 196). Este cenário conduziu à produção de novas autoridades, que passaram a ser responsáveis pela construção de inovadoras esperanças. $\mathrm{O}$ saber científico e a expertise profissional tornaram-se as 
referências centrais, no que concerne à vida, saúde, corpo, doença e morte. Nossas mortes, assim como nossas vidas, foram, então, colocadas nas mãos de especialistas.

A categoria esperança adquire novos significados, ao se tornar objeto do processo de medicalização da sociedade. Cabe aqui apresentar a definição de Peter Conrad (2007: 4), a "medicalização descreve o processo pelo qual problemas não médicos passam a ser definidos e tratados como questões da saúde, geralmente como doenças ou transtornos". Faz-se ainda necessário enfatizar a crescente penetração do discurso, dos saberes e das práticas biomédicos em maior número de esferas da vida.

A partir do século XIX e, sobretudo, do XX, trata-se da produção de corpos saudáveis e de pessoas autônomas. Segundo Duarte (1999: 27), as diferentes "estratégias de maximização da vida e otimização do corpo, a clínica, a higiene, a assepsia, a anestesia, a odontologia, a ginecologia, a gerontologia, a psicofarmacologia - todas essas especialidades só puderam surgir em função da sistemática exploração do corpo humano como sede da busca indefinida, eternamente perfectível, da exacerbação da sensibilidade, do refinamento ou intensificação do prazer". Para Campbell (2001), o hedonismo moderno opera com uma estratégia qualitativa, dirigida à busca de maior intensidade dos sentidos.

Seja em caso de doença, seja na estética ou performance corporal, as demandas se voltam para os recursos da medicina. Esta instituição e seus profis- sionais respondem com drogas - para transtorno da ereção ou da atenção, depressão, ansiedade, rugas, entre outras possibilidades -, com exercícios, recomendações alimentares e/ou comportamentais, com intervenções cirúrgicas e inovadoras tecnologias, voltadas para o incremento das capacidades humanas (enhancement), para a reprodução, manutenção ou prolongamento da vida. Nas palavras de Walter (1996a: 83): "a medicina diz ao paciente que ele não é imortal, que ele tem uma forma de câncer tratável, com boas possibilidades de viver ainda por alguns anos". São criadas novas estratégias e novos significados, na produção de esperança.

Diante de cada evento faz-se necessário um posicionamento. Novas expectativas são geradas, a partir de saberes científicos inovadores e da divulgação de tecnologias. Vale indicar que este processo também conduz à produção de sentimentos, associados a cada possibilidade de prática ou de normatização. Como exemplo, em face de alguma dificuldade na esfera da reprodução, o casal - hetero ou homossexual - conta com um leque de opções, como fertilização in vitro, doação de óvulos, de espermatozoides, "barriga de aluguel", entre outras. Cada escolha é capaz de propiciar a emergência de emoções, tanto entre os envolvidos diretamente na situação quanto de estranhos, situados à distância. Assim, em face de cada possibilidade, há uma via de mão dupla, em relação à produção de sentimentos. A democratização das informações com o advento da internet e seus recursos - também conduziu a marcantes 
alterações na postura do consumidor e cidadão. Como consequência, novas formas de relação médico-paciente, emoções e sentimentos, além de inovadoras modalidades de processos de tomadas de decisão, no que tange à doença, tratamento, sofrimento e morte (Wirtz et al. 2006: 116; KarnieliMiller \& Eisikovits 2009: 1; Menezes 2011a: 1429). Novas tecnologias acarretam o surgimento de práticas sociais e costumes - como o compartilhamento das imagens de ultrassom do feto (Petchesky 1987: 263) -, que propiciam a emergência e a expressão de variados sentimentos. Dentre eles, destaca-se a esperança.

\section{SÉCULO XX: O HOSPITAL E SEUS PROFISSIONAIS; A DOENÇA, OS DOENTES E A ESPERANÇA}

O século XX é caracterizado pela expansão e capilarização do processo de medicalização. Neste período, a vida, quando comparada com tempos anteriores, tornou-se mais previsível, exigindo de cada pessoa um grau mais elevado de antecipação, e de controle de sentimentos e comportamentos. A partir do término da Segunda Grande Guerra houve um grande desenvolvimento de recursos tecnológicos direcionados à criação e manutenção da vida, como o aperfeiçoamento do respirador artificial, da diálise renal, entre outros. As Unidades de Tratamento Intensivo são criadas nesta época, assim como várias modalidades de aparelhagem, voltadas ao prolongamento da vida. Por vezes, o uso de tecnologia acarretava - e ainda acarreta - uma ex- tensão do tempo de vida, à custa de sofrimento para o enfermo e seus familiares. No final da década de 1960, com os transplantes de órgãos vitais - como o coração - a morte, em decorrência de enfermidades, passa a ser cada vez mais objeto de afastamento, para os bastidores da vida social (Elias 2001: 8). O hospital e seus profissionais são encarregados de uma organização da assistência que produz o ocultamento da morte e dos mortos.

No final dos anos 1960 e início dos 1970 surgem críticas aos excessos de poder do médico, sobretudo em contexto hospitalar (Sudnow 1967; Glaser \& Strauss 1965; 1968; Kübler-Ross 1969). A produção analítica e crítica sobre a gestão médica - em especial, em torno da trajetória em direção à morte - aponta um processo de despersonalização dos doentes internados em hospitais (Goffman 1972), de ocultamento da própria condição ao enfermo, efetuado pela equipe de saúde, além de uma assistência impessoal, mecânica e asséptica.

A expressão "modelo de morte moderna" é criada por Ariès (1981, 2003), em referência a esta forma de administração do processo do morrer, em instituição hospitalar. $\mathrm{Na}$ sociedade tradicional, o grande medo, em caso de adoecimento e morte, se centrava no Juízo Final. Com a perda da transcendência e dos valores religiosos, o medo da morte não se situa mais em outra dimensão ou esfera: o foco incide sobre a vida terrena. A figuração da morte é substituída: do esqueleto com a foice, que ceifa muitas vidas ao mesmo tem- 
po, nas epidemias ou "pestes", para a imagem de um doente no século XX, internado em moderna Unidade de Tratamento Intensivo, com seu corpo invadido por tubos e conectado a máquinas, isolado e solitário, sem possibilidade de qualquer tipo de expressão (Menezes 2006).

Os excessos de poder do médico e o uso das novas tecnologias acarretaram questionamentos sobre os direitos de autonomia dos doentes no processo de tomada de decisões de suas vidas, sofrimento e morte. No Ocidente, nos anos 1950 e 1960 era prática corrente entre médicos o ocultamento da verdade aos pacientes (e, por vezes, de seus familiares), de modo que a tomada de decisões constituía responsabilidade exclusiva do profissional. Esse panorama se modificou inicialmente nos Estados Unidos (e, posteriormente, em grande parte dos países do ocidente), tanto em decorrência de mudanças no aparato médico - pelo número crescente de processos legais contra instituições e profissionais de saúde quanto da emergência de movimentos da sociedade civil, em prol dos direitos dos doentes. Como exemplo, em muitos países, até poucas décadas, o médico escolhia o tratamento, sem diálogo prévio com o doente e/ou seus familiares. No Brasil, é de amplo conhecimento que este quadro ainda ocorre, especialmente em unidades públicas de saúde, nas quais há marcada diferença de pertencimento social, entre equipe de saúde e usuários (Menezes 2011a).

O desenvolvimento tecnológico também conduziu a profundas trans- formações na concepção de vida e na produção de novos meios de reprodução (Luna 2007), e a marcantes alterações no processo do morrer e no próprio conceito de morte. A morte deixa de ser um fenômeno pontual, caracterizado pela parada cardíaca e/ ou respiratória. Comitês são criados, para debater os parâmetros que determinam o término da vida. Por fim, emerge um novo critério e uma nova nomenclatura: a morte cerebral. Assim, com o desenvolvimento das técnicas e tecnologias médicas no século XX foi preciso repensar a definição de morte e, especialmente, os princípios éticos que regem a ação do médico.

As fronteiras da morte são ampliadas, graças à possibilidade de reanimação, alimentação e respiração artificiais. Surgem novas questões, associadas aos direitos humanos e à redefinição de saúde. Não se trata mais da ausência de doença, mas de "completo bem-estar". A preocupação com os abusos em campos de concentração da Segunda Grande Guerra e a proteção da pessoa ganha renovada repercussão. As fragilidades dos sistemas normativos são objeto de questionamentos. Desde então, instituições e países buscaram uma regulamentação para promover, proteger e preservar a dignidade da pessoa e de sua vida. Tornou-se premente a revisão do conteúdo de leis e normas, para maior efetividade das garantias do Estado a seus cidadãos. $\mathrm{O}$ sistema de proteção internacional dos direitos humanos surge como a principal proposta, voltada a afiançar esta proteção, de modo a gerar e determi- 
nar o valor da pessoa humana no contexto contemporâneo. Nesse processo, o tema da saúde passa a integrar o rol dos direitos humanos.

A saúde, suas instituições e profissionais se tornam objeto de políticas, normas e práticas. Não se trata somente de prestar uma assistência ou de prevenir doenças, mas de também garantir um exercício de autonomia ao enfermo. Este personagem não deve ser mais nomeado como paciente: ele passa a ser designado de usuário, torna-se um cidadão, que conta com um conjunto de direitos.

Este amplo processo, que conduziu a grandes transformações nas formulações de corpo, vida, saúde, doença e morte, também propiciou diferentes modos de elaboração da esperança. Ela pode ser dividida em níveis ou graus, que variam de acordo com o momento. Diante da aparição de algum sinal de perturbação, transtorno, sofrimento ou dor, surgem expectativas. Geralmente, o primeiro movimento é a busca por informações e atendimento médico, o que não exclui uma consulta religiosa. Espera-se receber um diagnóstico, uma vez que a nomeação é importante em qualquer grupo, cultura ou sociedade. A partir de uma atribuição de um nome para o problema, seja de uma doença, de "encosto" ou acerca de qualquer outra condição, é possível organizar a busca por recursos, para o restabelecimento do equilíbrio. A seguir, a esperança é dirigida à existência de práticas e meios para a resolução do transtorno ou do problema, o que pode significar tanto uma expectativa de se tratar de enfermidade passível de cura quanto de acesso a atendimento e aos bens de consumo para o tratamento. A diferença na produção destas duas modalidades de esperança se baseia na inserção social. As críticas a uma assistência excessivamente tecnologizada, na maior parte das vezes, é originária de camadas médias intelectualizadas, enquanto as demandas pelo uso de todos os recursos e aparelhagem geralmente é proveniente de segmentos populares.

No entanto, a problemática não se resume à possibilidade (ou não) de acesso à assistência pública ou privada, e/ ou de escolha por determinado tipo de tratamento. Em muitas situações, a doença não é curável: trata-se de condição crônica. A esperança pode então se voltar para o controle da enfermidade e para a qualidade de vida do doente. Esta expressão, difundida a partir da década de 1990, passa a integrar as prescrições da biomedicina, em seu processo de capilarização da medicalização, que se infiltra nas mais variadas instâncias e esferas da vida cotidiana.

Afinal, trata-se de ampliar as possibilidades de fruição do viver e de propiciar aumento da expectativa do tempo de vida. A meta é afastar a morte. A utopia é alcançar a vida eterna, com qualidade. À biomedicina são atribuídos os encargos desta produção de um indivíduo autônomo, com o direito de fruição da vida, com bem-estar.

Entretanto, esta não é a única alternativa, em face do surgimento de algum problema de saúde. No século XX, a esperança se centrou na cura ou no 
controle da doença. No que tange às críticas ao ocultamento do diagnóstico e prognóstico, efetuado pelo médico, as expectativas se voltaram para uma relação entre médico e paciente baseada na transmissão de dados acerca da situação. Assim, o enfermo pode efetuar suas escolhas - se assim o desejar.

A assistência em saúde no século XX é eminentemente racionalizada, produtora de uma super medicalização do final da vida do doente, e de sua perda de autonomia. A formação do médico é caracterizada pela transmissão de um modelo de prática hospitalocêntrico, baseado na cura das enfermidades, em "pacientes ideais", que "respondem" ao tratamento. Para o médico e para o hospital, antes de tudo, a morte se tornou um fracasso: é, pois, conveniente que ela perca sua importância central e cesse de mobilizar recursos e energias. De acordo com Herzlich (1993: 6), isso não significa que os profissionais de saúde, em seu exercício cotidiano, sejam insensíveis ao sofrimento. Para esta autora, a angústia está sempre presente no hospital, qualquer que seja a indiferença ou a brutalidade das rotinas institucionais.

Não se trata aqui de apontar vítimas ou culpados, vinculados ao modelo de assistência em saúde dominante no século XX - e que assim permanece em diversos contextos -, caracterizado por uma organização racionalizada do trabalho, considerada por muitos como "desumana". Antes, trata-se de refletir sobre a construção de ideários, que conduzem à produção de diferentes tipos de esperança.

\section{PROCESSO DO MORRER E ESPERANÇAS}

Diante das críticas ao "modelo de morte moderna", responsável pela exclusão do doente do processo de tomada de decisões, ao silenciamento de sua voz e, por fim, pela produção de uma morte solitária e "desumana", surgem novas propostas de gestão dos cuidados dos enfermos no hospital, além de mudanças na relação de poder entre médico e paciente.

Nos Estados Unidos, a partir dos anos 1960 e 70, médicos sofrem processos judiciais, quando são acusados de ocultamento da verdade aos pacientes e familiares (Daniel 1999; Van Dongen \& Faizang 2005; 2006). Assim, estes profissionais são demandados a assumir novos posicionamentos, em seu trabalho. A concepção de que o conhecimento do verdadeiro diagnóstico pode acarretar depressão no enfermo se altera, especialmente em caso de câncer. Os oncologistas são os primeiros médicos a mudarem seu comportamento, na direção de um diálogo franco com seus pacientes.

Na década de 1970, nos Estados Unidos, são fundadas organizações civis com reivindicações que abrangeram desde o direito de "morrer com dignidade" até a regulamentação da eutanásia (Menezes 2004). Após certo tempo, surge um discurso que propõe um novo modo de prática em relação à morte, com transformações na relação de poder entre equipe de saúde e enfermo (e seus familiares). $\mathrm{O}$ foco incide sobre a humanização da assistência ao morrer e, também, sobre o direito de autonomia do enfermo. $\mathrm{Na}$ nova modalidade de relacionamento, o médico 
deve transmitir informações ao doente, sobre seu quadro clínico, prognóstico e alternativas terapêuticas, para que este possa optar e decidir, com o suporte de sua família. Vale referir que, neste modelo inovador de gestão dos cuidados, os familiares se tornam importantes personagens: por vezes são considerados pelos profissionais da assistência como membros da equipe de saúde.

Em 1967, Cicely Saunders funda o primeiro hospice em Londres, instituição exemplar do novo modelo de assistência a doentes terminais: os cuidados paliativos (CP). Com a epidemia de AIDS, surgida na década de 1980, e o desenvolvimento de técnicas de combate a doenças degenerativas, em especial, o câncer, as dores e sintomas produzidos por estas enfermidades, outros hospices e serviços de atendimento domiciliar em CP são criados.

A proposta dos $\mathrm{CP}$ - ou o projeto hospice - busca minorar o máximo possível a dor e os demais sintomas dos enfermos e, simultaneamente, possibilitar maior autonomia e independência dos mesmos. Do silêncio, ocultamento e negação passou-se à colocação da morte em discurso, no final do século XX. Um modelo ideal é difundido inicialmente nos países anglo-saxões e, pouco depois, para outros países do ocidente. A proposta se centra em uma equipe multiprofissional, dirigida a uma assistência à "totalidade biopsico-social-espiritual" do paciente e de seus familiares. O ideal é que a pessoa que está morrendo tenha controle sobre o processo de morte, realizando escolhas a partir das informações so- bre as técnicas médicas e espirituais que considerar adequadas (Menezes 2004:37).

Neste modelo, o doente recebe uma nova denominação: a de FPTC: "fora de possibilidades terapêuticas de cura". Ao enfermo assim categorizado é atribuída uma tarefa primordial: aceitar o término de sua vida, efetuar escolhas, construindo uma trajetória na direção de uma "boa morte". Desta maneira é possível a produção do ideal paliativista: "morrer bem", com dignidade, a partir da resolução das "pendências" materiais, afetivas e emocionais. Este modelo inovador de assistência ao processo do morrer recebe a nomenclatura, de estudiosos das ciências sociais, de "modelo de morte contemporâneo", "neo-moderno" ou "pós-moderno".

Desde a fundação do primeiro hospice, este modelo de atenção ao processo do morrer vem se difundindo em planos intimamente associados, mas passíveis de distinção. O primeiro é composto pela produção social e pela divulgação do ideário em meios de comunicação. O segundo contém a criação e o desenvolvimento de uma nova disciplina e especialidade - os CP -, baseada em saberes científicos, além da publicação de manuais técnicos e da fundação de entidades profissionais específicas. Por fim, o terceiro plano refere-se à implementação de serviços de assistência paliativa e, mais do que isso, a incorporação desta modalidade de atendimento em políticas públicas de saúde.

Seja em livros técnicos, seja em obras de auto-ajuda, emerge um discurso comum: o do direito ao "morrer bem", 
com autonomia e "dignidade". Assim, a assistência em CP passa a ser incluída no conjunto dos direitos do doente: direito de não sofrer, de receber atenção, para produção de uma "boa morte", sem dor. $\mathrm{Na}$ cultura do Individualismo, que valoriza a vida única e singularmente vivida, são criados os conceitos do "morrer bem" e de "qualidade de morte".

A "boa morte" é definida como a que é aceita, escolhida e produzida por quem está morrendo. Os profissionais de CP e os militantes desta filosofia veiculam a ideia de que se trata de uma causa antitecnológica, em prol do desenvolvimento do ser humano, na direção de sua realização e encontro com sua "essência", em especial, no contato com a natureza. Estes trechos de frases, utilizados na divulgação de congressos de CP, são ilustrativos: "um canto de esperança" e "dar vOZ aos pacientes" (Menezes 2009: 53). Técnicas de visualização e mentalização para doentes terminais são criadas pelos paliativistas, com o objetivo de propiciar a despedida da vida, o que pode acarretar a produção de uma morte aceita e pacífica (Menezes 2009: 65).

Em oposição ao ocultamento do morrer efetuado pelo aparato médico, os militantes paliativistas postulam a construção de uma morte compartilhada socialmente. Em oposição ao que Ivan Illich (1975) designou como "expropriação da própria morte", a proposta de que o doente mantenha sua autonomia, de modo a exercer controle sobre os mínimos detalhes, tanto sobre o processo do morrer quanto nas deliberações acerca dos procedimentos com relação ao seu corpo. Indo além, o morto pode - e deve - escolher e deixar registrado, também, os nomes das pessoas com direito a participar das cerimônias após o óbito e o papel que elas devem desempenhar então.

Neste sentido, os CP oferecem um conjunto de esperanças ao enfermo FPTC ou, em outros termos, ao "morredor" ou doente terminal. Uma sequência pode ser traçada, a partir do exame de manuais, de livros-texto de medicina paliativa, de material de divulgação do ideário, de produção cultural, de observação etnográfica de congressos de CP e de entrevistas com profissionais da especialidade.

Como exemplo, no caso de câncer, a partir da constatação do avanço da doença, apesar das tentativas terapêuticas, como cirurgia, radio e quimioterapia, além do uso de outros recursos, a primeira mensagem do paliativista deve ser, de acordo com Saunders: "eu me importo com o fato de você ser você, me importo até o último momento de sua vida e faremos tudo o que estiver a nosso alcance, não somente para ajudá-lo a morrer em paz, mas também para você viver até o dia da morte" (Pessini 2001: 208).

Este texto veicula dois conteúdos: o primeiro é a crítica ao modo de atendimento tido como frio e impessoal, que abandona o doente, sob a justificativa de que "não há mais o que fazer". A seguir, a afirmação de uma medicina (paliativa) que se baseia na compaixão humana, o que significa não somente uma ajuda para morrer em paz, sem dores, pendências ou mágoas quanto 
voltada para a vida, e não para uma sobrevida. Tal posicionamento reforça as ideias de qualidade de vida, de exercício do livre arbítrio e de foco sobre a intensidade na fruição do viver. Em outros termos, indica a centralidade do subjetivismo, que significa a ênfase na representação da escolha pessoal do sujeito, seu livre arbítrio, além do hedonismo (Duarte et al 2006: 18). Tais aspectos integram a ideologia do Individualismo (Dumont 1993).

A proposta da filosofia hospice e da assistência em CP foi formulada a partir do contato de Saunders com pacientes oncológicos, com doença avançada, objeto de abandono por parte da equipe médica, em situação de grande sofrimento, com muita dor e outros sintomas. A ideologia paliativista e o hospice atraíram os primeiros doentes com AIDS, interessados na instituição exemplar desta modalidade de assistência, sobretudo pelo respeito à autonomia individual.

$\mathrm{O}$ discurso dominante sobre o câncer na sociedade ocidental moderna é centrado na categoria esperança (Lupton 1998: 67). Esta doença é representada como desafio à racionalidade: "parece que o câncer - como consequência da desordem social - inscreve a desordem analógica no corpo da pessoa doente, conduzindo à morte" (Pinell 1987: 27; 1992). A esperança está associada ao discurso militar e a metáforas de invasão (Sontag 2007). Em uma primeira etapa da doença, trata-se de vencer o inimigo, de não se deixar levar pelo desespero, de não desistir. Este tipo de discurso repousa na comunicação franca acerca do diagnóstico e prognóstico.
Entretanto, quando a doença avança, apesar de todos os esforços de médico e paciente, novos tipos de esperança são construídos. $O$ fracasso não mais reside na impossibilidade de bloquear o avanço do inimigo. A falha se transforma e pode ser a negação da iminência da morte, a perda da oportunidade de desenvolvimento e aperfeiçoamento pessoal, para uma elaboração da vida e da morte.

A produção de esperança do doente FPTC, em sua trajetória na direção da morte pode variar, de acordo com a construção de significados para vida e pessoa. Assim, tanto é possível uma incorporação do ideário paliativista e do modelo das cinco frases (eu te amo, perdoe-me, eu te perdôo, obrigada e adeus) quanto dos argumentos da causa da eutanásia e do suicídio assistido - centrado no direito ao controle da própria morte e das condições do morrer.

Em investigação com sobreviventes de diversos tipos de câncer, Little e Sayers (2004: 1335) identificaram que a emoção da esperança estava associada a diferentes objetivos, que variavam segundo a fase da doença em que se encontravam. De acordo com os autores (Little e Sayers 2004: 1336), havia discursos do enhancement (da intensificação), da restituição, do heroísmo, da normalidade ("vida que segue") e, na proximidade do falecimento, da percepção e produção de sentidos para vida e morte.

Em levantamento bibliográfico com uso do descritor esperança (hope) surgiram muitos artigos, a maioria com estudos sobre doentes com câncer e AIDS, com títulos ilustrativos, como 
While there's life... hope and the experience of cancer (Little \& Sayers 2004:1329); Hope and hoping in the talk of dying cancer patients (Eliott \& Olver 2007:138); Medical promise and the recalibration of expectation: hope and HIV treatment engagement in a trasitional setting (Rhodes et al. 2009:1050), entre outros. Além disso, o vol. 26, no 75 do periódico Estudos Avançados da USP, de maio/ago 2012, conta com um dossiê intitulado Sociologia e Esperança. Estes dados indicam a importância do tema esperança na contemporaneidade.

\section{CONSIDERAÇÕES FINAIS}

No século XXI, o acompanhamento das mudanças de legislação em torno da gestão contemporânea da morte na sociedade ocidental evidencia a crescente demanda em prol de controle sobre a própria morte (Menezes \& Ventura 2013). Cada vez há maior número de países com leis referentes aos direitos de interrupção de tratamento, de ortotanásia, de morte digna, ao suicídio assistido ou à eutanásia, seja ela ativa ou passiva. A este panorama somam-se as solicitações de autorização judicial para interrupção de alimentação, hidratação e medicamentos, além de retirada de aparelhagem para manutenção da vida, como respirador artificial, por exemplo (Menezes 2011b). A maioria dos pedidos é de enfermos com avanço da doença, sem perspectivas de cura e de controle da dor e dos sintomas. O caso de Chantal Sébire, na França, é exemplar. Esta mulher tinha um tipo de câncer muito raro no rosto, que provocava cegueira e dores intensas. Ela se tornou conhecida em seu país como a mulher sapo, pela deformação de sua face.

A mídia também veicula outros tipos de solicitação na direção da morte, além do caso de avanço da doença com dores e outros sintomas. Os pedidos do espanhol Ramon Sampedro e do australiano Christian Rossiter, com diferença de um período de cerca de dez anos, são semelhantes. Ambos ficaram tetraplégicos após acidentes: o primeiro, em mergulho, e o segundo, por atropelamento. Os dois homens contavam com cuidados - o primeiro na casa de seu irmão, com a dedicação de sua cunhada, em cidade pequena do interior da Espanha; e o segundo em um hospice. Ambos estavam lúcidos e conscientes, interagiam e demandaram oficialmente o direito de suicídio assistido e de eutanásia passiva, respectivamente.

As respostas foram divergentes. $\mathrm{O}$ pedido de Sampedro foi recusado pela corte espanhola. Ele conseguiu morrer graças ao apoio de uma ONG (Derecho a morrir), em 1998. Ele viveu trinta anos quadriplégico e considerou que não fazia mais sentido sua vida. Já a demanda de Rossiter foi aceita e aprovada pela corte australiana. Ele morreu em 2009, cinco semanas após a suspensão de medicamentos, alimentação e hidratação. A justificativa de sua solicitação se centrou na perda da autonomia, pois "não conseguia mais exercer uma função humana básica: enxugar as próprias lágrimas" (Menezes 2011b:137).

O terceiro tipo de demanda de interrupção de recursos para manutenção 
da vida se refere a situações nas quais o doente não possui mais consciência e suas funções corporais são mantidas pelo uso de aparelhagem. O demandante é geralmente um parente do enfermo. O caso da italiana Eluana Englaro, que permaneceu dezessete anos em estado vegetativo, é exemplar. O pedido do pai (representante da família) foi aprovado pela Suprema corte italiana e a alimentação e hidratação artificiais foram interrompidas.

Seja em qual for o tipo de demanda ou de patologia, observa-se a produção de uma esperança, comum a todas as situações: a de encerramento da vida. Trata-se de casos nos quais as condições de fruição da vida se transformaram radicalmente. Neste sentido, a morte passa a carrear o significado de libertação de um viver com sofrimento, perda de autonomia e sem dignidade. Este posicionamento, dos defensores do direito ao suicídio assistido e à eutanásia, recebe críticas e forte oposição, por parte dos militantes da causa da boa morte. Para os paliativistas, o doente que recebe uma assistência adequada e suporte social, não solicita o direito de intervenção para morrer. Ainda de acordo com os defensores dos CP (Hennezel 2004), aqueles que desejam o término de suas vidas perdem a possibilidade de uma boa conclusão do viver. Indo além, abrem mão de uma morte com plena consciência, em êxtase.

Cabe aqui indicar a existência de convergências, entre os posicionamentos: geralmente, os contrários ao direito de eutanásia e de suicídio assistido também se opõem à legalização do aborto.
Os limites da vida - início e fim - contam com algumas semelhanças, no que concerne aos direitos. Uma diferença é primordial: o feto ainda não é uma pessoa, não conta com uma trajetória. Ele está contido no corpo de uma mulher, que pode optar pelo que deseja. O doente terminal possui um percurso de vida e tem condições de efetuar escolhas sobre sua vida, corpo e sofrimento (Menezes \& Gomes 2011:90).

No século XXI, a crescente autorização legal de aborto e de leis de morte digna, suicídio assistido e/ou de eutanásia evidencia a preeminência do direito de autonomia individual, como importante valor da sociedade ocidental contemporânea. De acordo com Dworkin (2003: 343), "para nós, o fato de viver de acordo com nossa liberdade é tão importante quanto o fato de possuí-la”. Assim, a esperança se volta para o livre arbítrio, diante de situação liminar, como no avanço da doença.

Recentemente também são criados novos termos e expressões, como "tecnologias da esperança" (Leibing \& Tournay 2010:3), em referência ao conjunto de procedimentos biotecnológicos definidos como ferramentas médicas dotadas de uma capacidade potencial de preservar ou prolongar a vida. Um bom exemplo é a pesquisa e uso de células-tronco, em diferentes condições patológicas. Em face da criação desta inovadora tecnologia, observa-se a emergência de sentimento de esperança e, em alguns contextos, o surgimento de movimentos de militantes (pacientes e seus familiares), com demandas pelo acesso ao recurso. 
De fato, a tecnologia não é de esperança, mas sua criação propicia o surgimento de esperança, revelando um tipo de vínculo social, que conecta os campos de conhecimentos, as formas de normatização e os modos de subjetivação, em uma dada cultura (Leibing \& Tournay 2010: 11). A esperança efetua uma produção de nexos em torno de desejos individuais, subjetivos e projetos coletivos.

Portanto, seja na expectativa de alcançar uma "bela finalização da vida, de modo pacífico e harmonioso" (Menezes 2004:183), seja na produção de um suicídio assistido, com suporte de ONG específica, como a suíça Dignitas ou, ainda, em negociações em torno da eutanásia (Norwood 2009), a esperança repousa em um projeto vinculado à biomedicina, seus profissionais e saberes. Indo além, cada modalidade de esperança passa a consistir em uma espécie de motor social, com capacidade de incitar a produção de sentimentos à distância (Boltanski 1993) que, por sua vez, necessariamente provoca posicionamentos morais e políticos, em torno de demandas jurídicas.

$\mathrm{Na}$ contemporaneidade, observa-se a crescente ênfase na produção de esperança. Cada vez mais a vida e seu valor são afirmados, seja a vida nesta dimensão, seja em outra esfera, após a morte (Menezes 2011c:143). Indo além, há a esperança de desenvolvimento de tecnologias para retorno à vida, após o descongelamento da pessoa. O mito do congelamento do corpo de Walt Disney ou da cabeça de Timothy Leary alimenta a busca por empresas que congelam cadáveres em nitrogênio líquido, nos Estados Unidos. Há, atualmente, muitos corpos mantidos desta maneira, na esperança da criação de recursos inovadores para a reanimação destes mortos.

Por um lado, o movimento contrário à legalização do suicídio assistido e da eutanásia considera o pedido de interrupção da vida como prova da má qualidade da assistência paliativa e de carência de suporte social. Este posicionamento é indicativo de uma dificuldade de aceitação da possibilidade de ausência de esperança e do direito de considerar que não é mais possível elaborar qualquer significado para a própria vida.

Por outra perspectiva, o aumento do número de países com legislações que autorizam o suicídio assistido, a eutanásia, a interrupção de recursos terapêuticos ou para manutenção da vida, evidencia a aceitação de inexistência de condição de fruição da vida ou, em outros termos, de vida com dignidade. Nesse sentido, o direito de se manter vivo não pode ser confundido com o dever de se manter vivo. Por vezes, esta situação é objeto de diagnóstico psiquiátrico, como de depressão, e de intervenção médica. Contudo, tratase antes do reconhecimento do direito, que pode - e deve - se estender, desde a escolha dos tratamentos até a decisão pelo término da própria existência, de forma considerada digna. Esta condição é produto de uma cultura que valoriza a autonomia individual e respeita as diferenças de crenças. O debate está em pauta no ocidente. Cabe a cada grupo, cultura ou sociedade refletir sobre suas escolhas e reivindicar seus direitos. 


\section{REFERÊNCIAS}

Adam, P. \& C. Herzlich. 2001. Sociologia da doença e da medicina. Bauru: EDUSC.

Ariès, P. 1981. O bomem diante da morte. Rio de Janeiro: Francisco Alves.

2003. História da morte no Ocidente. Rio de Janeiro: Ediouro.

Boltanski, L. 1993. La souffrance à distance. Morale bumanitaire, médias et politique. Paris: Métailié.

Burke, P. 2012. A esperança tem história? Estudos Avançados 26 (75): 207-218.

Campbell, C. 2001. A ética romântica e o espirito do consumismo moderno. Rio de Janeiro: Rocco.

Conrad, P. 2007. The medicalization of society. Baltimore: The Johns Hopkins University Press.

Crapanzano, V. 2003. Reflections on hope as a category of social and psychological analysis. Cultural Anthropology 18(1): 3-32.

Daniel, A. 1999. Trust and medical authrity, in Health matters. A sociology of illness, prevention and care. Editado por A. Petersen \& C. Waddell, pp. 208-222. Buckingham: Open University Press.

Delumeau, J. 1989. História do medo no Ocidente, 1300-1800. São Paulo: Companhia das Letras.

Duarte, L. F. D. 1999. O império dos sentidos: sensibilidade, sensualidade e sexualidade na cultura ocidental moderna, in Sexualidade, o olhar das ciências sociais. Editado por M. L. Heilborn, pp. 21-30. Rio de Janeiro: Jorge Zahar.

2004. A sexualidade nas Ciências Sociais: leitura crítica das convenções, in Sexualidades e saberes: convenções e fronteiras. Organizado por A. Piscitelli, M. F. Gregori \& S. Carrara, pp. 17-59. Rio de Janeiro: Garamond.

Duarte, L.F.D., J.M. Jabor, E.C. Gomes, N. Luna. 2006. Família, reprodução e ethos religioso: subjetivismo e naturalismo como valores estruturantes, in Família e Religião. Editado por L. F. D. Duarte, M.L. Heilborn, M. L. Barros \& C. Peixoto, pp. 15-50. Rio de Janeiro: Contracapa.

Dumont, L. 1993. O Individualismo: uma perspectiva antropológica da ideologia moderna. Rio de Janeiro: Rocco.

Dworkin, R. 2003. Dominio da vida. Aborto, eutanásia e liberdades individuais. São Paulo: Martins Fontes.

Elias, N. 1994. O processo civilizador. Rio de Janeiro: Jorge Zahar. 2001. A solidão dos moribundos. Rio de Janeiro: Jorge Zahar.

Eliott, J. A. \& I.N. Olver. 2007. Hope and hoping in the talk of dying cancer patients. Social Science and Medicine 64:138-149.

Faizang, S. 2005. When doctors and patients lie to each other. Lying and power within the doctor-patient relationship, in Lying and Illness: power and performance. Editado por E. Van Dongen \& S. Faizang. Amsterdam: Het Spinhuis.

Faizang, S. 2006. La relation médecins-malades: information et mensonge. Paris: Presses Universitaires.

Foucault, M. 1979. Microfísica do poder. Rio de Janeiro: Graal.

1994. O nascimento da clínica. Rio de Janeiro: Forense Universitária.

Glaser, B. \& A. Strauss. 1965. Awareness of dying. Chicago: Aldine.

Goffman, E. 1972. Internados. Ensayos sobre la situación social de los enfermos mentales. Buenos Aires: Amorrortu.

Hennezel, M. 2004. Propositions pour une vie digne jusqu'an bout. Paris: Seuil.

Herzlich, C. 1993. Os encargos da morte. Rio de Janeiro: UERJ/IMS. 
Illich, I.1975. A expropriação da saúde. Nêmesis da medicina. Rio de Janeiro: Nova Fronteira.

Karnielli-Miller, O. \& Z. Eisikovits. 2009. Physician as partner or salesman? Shared decision-making in real-time encounters. Social Science \& Medicine 69: 1-8.

Kübler-Ross, E. 1969. On death and dying. Nova Iorque: MacMillan.

Leibing, A. \& V. Tournay. 2010. Les technologies de l'espoir. La fabrique d'une bistoire à accomplir. Québec: Presses de l’Université Laval.

Little, M. \& E.-J. Sayers. 2004. While there's life... hope and the experience of cancer. Social Science and Medicine 59:1329-1337.

Luna, N. 2007. Provetas e clones: uma antropologia das novas tecnologias reprodutivas. Rio de Janeiro: Fiocruz.

Lupton, D. 1998. Medicine as culture. Illness, disease and the body in western societies. London: Sage.

Marret, R. 1932. Faith, hope, and charity in primitive religion. Nova Iorque: MacMillan.

Menezes, R.A. 2004. Em busca da boa morte. Antropologia dos Cuidados Paliativos. Rio de Janeiro: Garamond/Fiocruz.

Menezes, R.A. 2006. Dificeis decisões. Etnografia de um centro de tratamento intensivo. Rio de Janeiro: Fiocruz.

Menezes, R. A. \& M. Ventura. 2013. Ortotanásia, sofrimento e dignidade: entre valores morais, medicina e direito. Revista Brasileira de Ciências Sociais 28(81): 213-259.

2009. Preparação para a morte: entre religião, medicina e psicologia, in Dinâmicas contemporâneas do fenômeno religioso na sociedade brasileira. Editado por E.C.Gomes, pp. 5373. Aparecida: Ideias \& Letras.

2011a. Entre normas e práticas: tomadas de decisões no processo saúde/ doença. Physis 21(4): 1429-1449. 2011b. Demanda por eutanásia e condição de pessoa: reflexões em torno do estatuto das lágrimas. Sexualidad, Salud y Sociedad 9:137-153.

2011c. Notas sobre a "experiência de quase-morte": interpretações e sentidos, in Cultura e sentimentos. Ensaios em antropologia das emoçoes. Editado por M.C. Coelho e C. B. Rezende, pp.143-167. Rio de Janeiro: Contracapa.

Menezes, R. A. \& E. C. Gomes. 2011. "Seu funeral, sua escolha": rituais fúnebres na contemporaneidade. Revista de Antropologia 54(1):89-131.

Norwood, F. 2009. The maintenance of life. Preventing social death through euthanasia talk and end-of-life care - lessons from The Netherlands. Durham: Carolina Academic Press.

Pessini, L. 2001. Distanásia. Até quando prolongar a vida? São Paulo: Ed. Do Centro Universitário São Camilo.

Petchesky, R. P. 1987. Fetal images: the power of visual culture in the politics of reproduction. Feminist Studies 13 (2):263-292.

Pinell, P. 1987. How do cancer patients express their points of view? Sociology of Health and Illness, 9 (1): 25-44.

Pinell, P. 1992. Naissance d'um fleau. Histoire de la lutte contre le cancer em France (18901940). Paris: Métailié.

Rhodes, T., S. Bernays \& K.J. Terzic. 2009. Medical promise and the recalibration of expectation: hope and HIV treatment engagement in a transitional setting. Social Science \& Medicine 68:1050-1059.

Sahlins, M.1997. O "pessimismo sentimental" e a experiência etnográfica: por que a cultura não é um "objeto" em via de extinção. Mana 3(1)41-73. 
Sontag, S. 2007. Doença como metáfora. AIDS e suas metáforas. São Paulo: Companhia das Letras.

Sudnow, D. 1967. Passing on. The social organization of dying. New Jersey: Prentice Hall.

Walter, T. 1996a. The eclipse of eternity. A sociology of the afterlife. Londres: MacMillan Press.

. 1996b. Facing death without Tradition, in Contemporary issues in the sociology of death, dying and disposal. Editado por G. Howarth e P. C. Jupp, pp. 193-204. Londres: MacMillan Press.

Wirtz, V., A. Cribb \& N. Barber. 2006. Patient-doctor decision-making about treatment within the consultation - a critical analysis of models. Social Science \& Medicine 62: 116-124.

Recebido em 03/02/2013.

Aprovado em 14/03/2013. 